\title{
Comparison of health care resource utilization and costs among patients with GERD on once- daily or twice-daily proton pump inhibitor therapy
}

This article was published in the following Dove Press journal:

ClinicoEconomics and Outcomes Research

20 April 2013

Number of times this article has been viewed

Reema Mody'

Debra Eisenberg²

Likun Hou ${ }^{2}$

Siddhesh Kamat ${ }^{2}$

Joseph Singer ${ }^{2}$

Lauren B Gerson ${ }^{3}$

'Takeda Pharmaceuticals International Inc, Deerfield, IL, ${ }^{2}$ HealthCore Inc, Wilmington, DE, ${ }^{3}$ Stanford University School of Medicine, Stanford, CA, USA

Correspondence: Lauren B Gerson Division of Gastroenterology, Stanford University School of Medicine, 450 Broadway Street, Pavilion C,

Mail Code 634I, Redwood City,

CA 94063, USA

Tel +l 6507245159

Fax +I 6504986323

Email lgerson@stanford.edu
Background: The purpose of this study was to assess differences in health care resource utilization and costs associated with once-daily and twice-daily proton pump inhibitor (PPI) therapy. Most patients with gastroesophageal reflux disease (GERD) achieve symptom control on once-daily PPI therapy, but approximately $20 \%-30 \%$ require twice-daily dosing.

Methods: Patients were $\geq 18$ years of age with at least one medical claim for GERD and at least two PPI claims from HealthCore's Integrated Research Database (HIRD ${ }^{\text {SM }}$ ) during 2004-2009. Patients were continuously eligible for 12 months before and after the index date (date of first PPI claim). Based on PPI dosing throughout the post-index period (quantity of medication dispensed/number of days supply), patients were classified as once-daily (dose $\leq 1.5$ pills per day) or twice-daily ( $\geq 1.5$ ) PPI users.

Results: The study cohort included 248,386 patients with GERD (mean age 52.8 \pm 13.93 years, $56 \%$ females) of whom $90 \%$ were once-daily and $10 \%$ were twice-daily PPI users. The DeyoCharlson Comorbidity Index for once-daily and twice-daily PPI users was $0.70 \pm 1.37$ and $0.89 \pm 1.54$, respectively $(P<0.05)$. More once-daily patients had claims for Barrett's esophagus ( $5 \%$ versus $2 \%, P<0.0001)$ than twice-daily patients. Post-index, higher proportions of twicedaily patients had at least one GERD-related inpatient visit (7\% versus 5\%), outpatient visit ( $60 \%$ versus $49 \%)$, and office visit $(48 \%$ versus $38 \%)$ versus once-daily patients $(P<0.0001)$. Mean total GERD-related health care costs were \$2065 $\pm \$ 6636$ versus $\$ 3749 \pm \$ 11,081$ for once-daily and twice-daily PPI users, respectively $(P<0.0001)$.

Conclusion: Patients receiving twice-daily PPI therapy were likely to have more comorbid conditions and greater health care utilization and overall costs compared with patients using once-daily PPI therapy.

Keywords: gastroesophageal reflux disease, proton pump inhibitors, health care resource utilization, database analysis

\section{Introduction}

Gastroesophageal reflux disease (GERD) is a highly prevalent gastrointestinal condition, and approximately $20 \%$ of the US population aged 25-74 years have reported experiencing GERD-related symptoms one or more times per week. ${ }^{1}$ It is associated with substantial impairment of health-related quality of life, decreased productivity, and considerable social and economic burden. ${ }^{2-4}$ Approximately $10 \%$ of patients with GERD have attributed work absences to the condition. ${ }^{5,6}$ Since 2006, GERD has been the most common gastrointestinal-related diagnosis in outpatient office visits, accounting for approximately $5 \%$ of all visits in the ambulatory setting. ${ }^{2,3,7}$

Proton pump inhibitors (PPIs), which have emerged as the drugs of first choice for GERD treatment, are indicated for once-daily dosing based on efficacy data from 
clinical trials conducted with daily dosing. ${ }^{8}$ Even though there is no evidence of improved efficacy at higher doses, ${ }^{9}$ twice-daily PPI dosing is not uncommon in clinical practice. ${ }^{8}$ There are limited published data regarding demographic factors for twice-daily PPI users, but twice-daily use has been associated with refractory GERD, ${ }^{10,11}$ erosive esophagitis, ${ }^{12}$ and laryngeal manifestations. ${ }^{13,14}$ Practice guidelines updated in 2005 by the American College of Gastroenterology state that it is reasonable to increase the dose of PPI beyond the approved dose in conditions of noncardiac chest pain, and in patients with partial response or breakthrough symptoms on standard doses, among others. ${ }^{15}$ In a recent survey-based study, Chey et al used self-reported patient data to evaluate utilization patterns for prescription PPIs and other GERDrelated medications among patients in a mixed-model Health Maintenance Organization plan. Of the 617 patients who completed the survey, $71 \%$ used PPIs once daily, 22.2\% used PPIs twice daily, and 6.8\% took PPIs more than twice a day on an as-needed basis; there was no significant demographic difference associated with twice-daily use of PPIs. ${ }^{16}$ Ahmed et al, examining the difference in practice patterns between ear, nose, and throat physicians $(n=782)$ and gastroenterologists $(n=565)$ in the management of GERD-related laryngitis by physician survey, found that more than $70 \%$ of ear, nose, and throat physicians empirically prescribed oncedaily PPI, while $57 \%$ of the gastroenterologists prescribed twice-daily PPI $(P<0.001) .{ }^{13}$ A recent study by Gerson et al found that $12 \%$ of treatment-responsive GERD patients required twice-daily therapy, compared with $30 \%$ of patients considered refractory. ${ }^{17}$

Despite prior studies describing dosage patterns and costs for GERD patients treated with PPIs, ${ }^{2-4}$ patient factors associated with PPI dosing and the potential economic impact of twice-daily treatment have not been fully assessed. The purpose of this study, which queried administrative claims in a large managed care database containing linked medical and pharmaceutical data, was to determine the differences in health care resource utilization and costs among GERD patients using once-daily versus twice-daily PPI therapy.

\section{Materials and methods}

\section{Data source}

This was a retrospective cohort study that utilized the HealthCore Integrated Research Database (HIRD ${ }^{\mathrm{SM}}$ ), an administrative claims repository that includes medical, pharmacy, and eligibility information for approximately 35 million commercially insured lives. The HIRD contains a broad, clinically rich spectrum of longitudinal claims data from 14 health maintenance organizations, point-of-service, preferred provider organizations, and indemnity plans in the northeastern, southeastern, mid-Atlantic, midwestern, and western regions of the US. This study included complete medical and pharmacy claims from the HIRD for claims submitted from January 1, 2004 through June 30, 2009. All the materials used in this nonexperimental retrospective study were handled in strict compliance with the Health Insurance Portability and Accountability Act of 1996. Patient confidentiality was preserved and the anonymity of all patient data was safeguarded throughout the study.

\section{Patient sample}

To be included in the study, patients were required to have at least one medical claim with an International Classification of Diseases, 9th edition (ICD-9) code for GERD (530.10, $530.11,530.12,530.19,530.81,530.13,787.1 x)$ within the study period (January 1, 2004 to June 30, 2009) and at least two pharmacy claims for a PPI within the study intake period (January 1, 2005 to June 30, 2008). The date of the first PPI pharmacy claim during the study intake period was identified as the index date. For inclusion, patients were required to have at least 12 months of continuous insurance eligibility both prior to and after the index date. Only patients who were at least 18 years of age at the index date were eligible for inclusion. The use of PPI therapy prior to the index date was not a basis for exclusion, suggesting that not all patients were necessarily newly initiated on PPI therapy. Patients who initiated dexlansoprazole (Dexilant ${ }^{\circledR}$, Takeda Pharmaceuticals International Inc, Deerfield, IL, USA) prior to the end of the 12-month follow-up period were excluded because dexlansoprazole was approved in January 2009, providing insufficient follow-up time.

\section{Categorization of once-daily and twice-daily PPI users}

PPI usage patterns were assessed each month during the 12-month post-index period and subsequently quarterly in order to determine dosage levels in the follow-up period. Based on the PPI dosing regimen, calculated as the ratio of the quantity of medication dispensed divided by the number of days supply, the once-daily regimen was defined as any ratio $<1.5$ and twice-daily dosing was defined as any ratio $\geq 1.5$. The reason for this designation was based upon the fact that some patients prescribed once-daily dosing may use higher doses on occasion, while some patients prescribed twice-daily PPI may not be compliant on a daily basis with twice-daily dosing. Using this formula, patients who had 
twice-daily dosing for at least 4 months in the follow-up period were considered twice-daily users for all outcomes of interest. Patients who did not receive PPI medication during a particular quarter were not captured in the dataset for either twice-daily or once-daily dosing for that quarter or used in any analyses, and were classified as nonusers. As part of the cut point selection process, we conducted a sensitivity analysis with different cut point criteria for twice-daily and once-daily PPI use.

\section{Outcome measures}

Demographic and clinical measures included age, gender, health plan type, physician specialty, geographic region, comorbid conditions, Deyo-Charlson Comorbidity Index, and the index PPIs of the study subjects. While the timing of PPI administration is an important factor regarding clinical efficacy for all PPIs except for dexlansoprazole, we were unfortunately not able to capture information regarding timing of PPI for patients in this study. In addition, we were unable to capture information regarding grade of esophageal injury, if any, during endoscopic examinations that might have been performed. The outcome measures were overall and GERD-related health care resource utilization and costs for once-daily and twice-daily PPI users in the 12-month post-index period. Both health care utilization and cost computations included inpatient admissions, emergency room and/or physician office visits, outpatient services, and pharmacy claims. Patients aged 65 years and older were excluded from all cost analyses, because the administrative claims data captured were for commercially insured patients only (ie, no capture of Medicare data).

\section{Statistical analysis \\ Univariate analyses}

Differences in treatment patterns between the once-daily and twice-daily dosing groups were evaluated using either Chi-square, Wilcoxon rank-sum, or Kruskal-Wallis tests in accordance with the distribution of the observed data. Descriptive statistics, using the nonparametric MannWhitney $U$ test for overall and GERD-related health care utilization and costs, were determined for the 12-month pre-index and post-index periods.

\section{Multivariate analyses}

Comparisons of resource utilization and costs for the two groups were evaluated using a generalized linear model to account for the non-normal distribution and skewed nature of the data. A two-part regression model was used to assess covariates (including age, gender, region, presence of Barrett's esophagus, distal contractile integral score, and twice-daily or once-daily PPI use) predicting for overall and GERD-related total costs. SAS version 9.3 software (SAS Institute, Cary, $\mathrm{NC}$, USA) was used for all analyses in this study.

\section{Results \\ Demographic and clinical characteristics}

Based on the eligibility requirements, 248,386 subjects were categorized as GERD patients; $90 \%$ were classified as once-daily and $10 \%$ as twice-daily PPI users. The sensitivity analysis using different cut point criteria for twice-daily and once-daily PPI categorization revealed no statistically significant differences. With regard to the demographic characteristics for the 12-month pre-index period, Table 1 shows that the mean age of patients on once-daily treatment was $52.67 \pm 13.97$ years and for the twice-daily-treated patients was $53.89 \pm 13.53$ years $(P<0.0001)$. Females comprised $55.21 \%$ and $58.21 \%$ in the once-daily and twice-daily treatment groups, respectively $(P<0.0001)$. Primary care physicians constituted the largest group of prescribers, at $62.84 \%$ for patients in the once-daily group and $51.34 \%$ for patients in the twice-daily group $(P<0.0001)$. Gastroenterologist services were sought by a smaller proportion of patients $(13.72 \%$ in the once-daily group and $22.31 \%$ in the twice-daily group, $P<0.0001$ ). The geographic distribution of patients was roughly similar in the central, southeast, and northeast regions of the US. There appeared to be a greater number of patients from western regions on twice-daily therapy $(P<0.0001)$, and more twice-daily patients were likely to be on lansoprazole $(34.7 \%)$ and pantoprazole (24.3\%) than on esomeprazole, omeprazole, or rabeprazole.

\section{Pre-index comorbidities and medications}

Table 2 reports the comorbidities and medication utilization patterns among twice-daily and once-daily patients in the 12-month pre-index period. Patients using PPI twice daily were more likely to have comorbidities and use other comorbidity-related medications. The mean Deyo-Charlson Comorbidity Index scores for the once-daily and twice-daily groups during this period were $0.70 \pm 1.37$ and $0.89 \pm 1.54$, respectively $(P<0.0001)$. In total, $2.1 \%$ of once-daily patients had medical claims for Barrett's esophagus compared with $5.0 \%$ of twice-daily patients $(P<0.0001)$. A substantial proportion of patients used PPIs and/or histamine ${ }_{2}$ receptor antagonists in the pre-index period, indicating that not all patients were naïve to antisecretory therapy. 
Table I Demographic characteristics in the 12-month pre-index period

\begin{tabular}{|c|c|c|c|c|c|}
\hline & \multicolumn{5}{|l|}{ Treatment type } \\
\hline & QD $(n=222,759)$ & & BID $(n=25,627)$ & & $P$-value \\
\hline \multicolumn{6}{|l|}{ Age on index date, $n, \%$} \\
\hline 18-24 years & 4,261 & $1.9 \%$ & 406 & $1.6 \%$ & $<0.0001$ \\
\hline $25-34$ years & 16,367 & $7.4 \%$ & 1,432 & $5.6 \%$ & \\
\hline $35-44$ years & 40,042 & $18.0 \%$ & 4,100 & $16.0 \%$ & \\
\hline $45-54$ years & 65,569 & $29.4 \%$ & 7,546 & $29.5 \%$ & \\
\hline $55-64$ years & 59,636 & $26.8 \%$ & 7,473 & $29.2 \%$ & \\
\hline $65+$ years & 36,884 & $16.6 \%$ & 4,670 & $18.2 \%$ & \\
\hline Mean (SD), median & $52.67(13.97)$ & 52.00 & $53.89(13.53)$ & 54.00 & $<0.0001$ \\
\hline \multicolumn{6}{|l|}{ Gender, n, \% } \\
\hline Female & 122,985 & $55.2 \%$ & 14,918 & $58.2 \%$ & $<0.000 \mathrm{I}$ \\
\hline Male & 99,774 & $44.8 \%$ & 10,709 & $41.8 \%$ & \\
\hline \multicolumn{6}{|l|}{ Physician specialty (\%) } \\
\hline Gastroenterologist & 30,553 & $13.7 \%$ & 5,718 & $22.3 \%$ & $<0.0001$ \\
\hline Primary care provider & 139,990 & $62.8 \%$ & 13,157 & $51.3 \%$ & \\
\hline Other specialist & 40,137 & $18.0 \%$ & 5,878 & $22.9 \%$ & \\
\hline Unknown/missing & 12,079 & $5.4 \%$ & 874 & $3.4 \%$ & \\
\hline \multicolumn{6}{|l|}{ Region (\%) } \\
\hline Northeast region & 19,920 & $8.9 \%$ & 2,215 & $8.6 \%$ & $<0.0001$ \\
\hline Central region & 73,858 & $33.2 \%$ & 7,297 & $28.5 \%$ & \\
\hline Southeast region & $6 I, 983$ & $27.8 \%$ & 5,834 & $22.8 \%$ & \\
\hline West region & 66,998 & $30.1 \%$ & $|0,28|$ & $40.1 \%$ & \\
\hline \multicolumn{6}{|l|}{ PPI on index date (\%) } \\
\hline Omeprazole (Prilosec) & 18,339 & $8.2 \%$ & 3,366 & $13.1 \%$ & $<0.0001$ \\
\hline Lansoprazole (Prevacid) & 75,548 & $33.9 \%$ & 8,903 & $34.7 \%$ & \\
\hline Rabeprazole (Aciphex) & 22,272 & $10.0 \%$ & 3,242 & $12.7 \%$ & \\
\hline Pantoprazole (Protonix) & 74,566 & $33.5 \%$ & 6,223 & $24.3 \%$ & \\
\hline Esomeprazole (Nexium) & 32,034 & $14.4 \%$ & 3,893 & $15.2 \%$ & \\
\hline
\end{tabular}

Abbreviations: BID, twice daily; PPI, proton pump inhibitor; QD, once daily; SD, standard deviation.

\section{Post-index health care utilization and costs}

Overall all-cause utilization

Overall health care utilization was greater for twice-daily PPI users, as shown in Figure 1. During the 12-month post-index period, all-cause utilization of inpatient hospitalizations and emergency room visits was slightly but significantly higher in the twice-daily group, with about one fifth of all patients incurring at least one visit. Use of outpatient services and physician office visits was highly prevalent; almost all patients in both groups made at least one outpatient visit. Similarly, almost all once-daily and twice-daily patients had at least one physician office visit in the 12-month postindex period.

\section{GERD-related utilization}

In the 12-month post-index period, significantly greater GERD-related health care resource utilization was reported for patients on twice-daily versus once-daily doses for inpatient hospitalizations, emergency room visits, outpatient services, physician office visits, and endoscopy procedures (Figure 2). The most remarkable differences in GERD-related utilization were seen in outpatient visits, physician office visits, and endoscopy procedures.

\section{Total overall cost}

Patients on twice-daily dosing incurred significantly greater all-cause costs for outpatient services, physician office visits, pharmacy claims, and emergency room visits in the 12-month post-index period (Figure 1). The mean overall costs associated with the twice-daily dosing group were almost $45 \%$ higher for outpatient services and almost $50 \%$ higher for physician office visits. The mean pharmacy cost was also about $60 \%$ greater for patients on twice-daily dosing versus those on once-daily dosing, and the mean cost for all-cause inpatient hospitalizations was roughly one third higher for the twice-daily dosing group.

\section{GERD-related costs}

Patients on twice-daily dosing had significantly higher GERD-related post-index health care costs than once-daily patients for outpatient services, physician office visits, endoscopy procedures, and pharmacy expenditure (Figure 2). Expenditure was more than two thirds higher for patients on 
Table 2 Medication utilization and comorbidities in the 12-month pre-index period

\begin{tabular}{|c|c|c|c|c|c|}
\hline & \multicolumn{5}{|c|}{ Treatment type } \\
\hline & \multicolumn{2}{|c|}{ QD $(n=222,759)$} & \multicolumn{2}{|c|}{ BID $(n=25,627)$} & $P$-value \\
\hline \multicolumn{6}{|l|}{ Pre-index GERD medications, n, \% } \\
\hline Omeprazole (Prilosec) & 4,079 & $1.8 \%$ & 1,108 & $4.3 \%$ & $<0.0001$ \\
\hline Lansoprazole (Prevacid) & 34,273 & $15.4 \%$ & 6,001 & $23.4 \%$ & $<0.0001$ \\
\hline Rabeprazole (Aciphex) & 18,173 & $8.2 \%$ & 3,020 & $11.8 \%$ & $<0.0001$ \\
\hline Pantoprazole (Protonix) & 25,623 & $11.5 \%$ & 2,929 & $11.4 \%$ & 0.7279 \\
\hline Esomeprazole (Nexium) & 23,331 & $10.5 \%$ & 3,221 & $12.6 \%$ & $<0.0001$ \\
\hline Prescription $\mathrm{H} 2 \mathrm{RAs}^{\dagger}$ & 15,112 & $6.8 \%$ & 2,218 & $8.7 \%$ & $<0.0001$ \\
\hline \multicolumn{6}{|l|}{ Other pre-index medications, n, \% } \\
\hline Antihypertensives & 61,762 & $27.7 \%$ & 7,594 & $29.6 \%$ & $<0.0001$ \\
\hline Antihyperlipidemics & 64,902 & $29.1 \%$ & 8,462 & $33.0 \%$ & $<0.000 \mathrm{I}$ \\
\hline NSAIDs & 59,788 & $26.8 \%$ & 7,237 & $28.2 \%$ & $<0.0001$ \\
\hline Antibiotics & 135,113 & $60.7 \%$ & 16,947 & $66.1 \%$ & $<0.0001$ \\
\hline Chemotherapy & 1,200 & $0.5 \%$ & 197 & $0.8 \%$ & $<0.0001$ \\
\hline \multicolumn{6}{|l|}{ Pre-index comorbidities, n, \% } \\
\hline Respiratory infections & 69,213 & $31.1 \%$ & 8,682 & $33.9 \%$ & $<0.0001$ \\
\hline Hypertension & 81,265 & $36.5 \%$ & 9,839 & $38.4 \%$ & $<0.0001$ \\
\hline Disorder of lipid metabolism & 359 & $0.2 \%$ & 49 & $0.2 \%$ & 0.2607 \\
\hline Cardiovascular disease & 44,521 & $20.0 \%$ & 6,408 & $25.0 \%$ & $<0.0001$ \\
\hline Barrett's esophagus & 4,568 & $2.1 \%$ & 1,272 & $5.0 \%$ & $<0.0001$ \\
\hline Esophageal stricture & 5,051 & $2.3 \%$ & 862 & $3.4 \%$ & $<0.0001$ \\
\hline Esophageal cancer & 216 & $0.1 \%$ & 96 & $0.4 \%$ & $<0.0001$ \\
\hline Duodenal ulcer & $\mathrm{I}, 4 \mathrm{I} 5$ & $0.6 \%$ & 284 & $1.1 \%$ & $<0.0001$ \\
\hline Esophageal ulcer & 0 & $0.0 \%$ & 0 & $0.0 \%$ & $\mathrm{~N} / \mathrm{A}$ \\
\hline Peptic ulcer disease & 2,600 & $1.2 \%$ & 416 & $1.6 \%$ & $<0.0001$ \\
\hline Deyo-Charlson Comorbidity & $0.70(1.37)$ & 0 & $0.89(1.54)$ & 0 & $<\left.0.000\right|^{\wedge}$ \\
\hline \multicolumn{6}{|l|}{ Index score, mean (SD), median } \\
\hline $\begin{array}{l}\text { Duration of disease (in years), } \\
\text { mean (SD), median }\end{array}$ & $2.98(1.28)$ & 2.88 & $3.14(1.33)$ & 3.07 & $<0.0001$ \\
\hline $\begin{array}{l}\text { Duration of GERD treatment } \\
\text { (in years) mean (SD), median }\end{array}$ & $2.95(1.14)$ & 2.94 & $3.00(1.18)$ & 2.99 & $<0.0001$ \\
\hline
\end{tabular}

Note: ${ }^{\dagger} \mathrm{H} 2 \mathrm{RA}=$ histamine 2 receptor antagonist. ${ }^{\wedge} P$-value from poisson regression with Pearson chi-square correction for over-dispersion; other $P$-values from Chi-square test; $\mathrm{p}$-values for duration of disease and for duration of GERD treatment from $t$-test.

Abbreviations: BID, twice daily; GERD, gastroesophageal reflux disease; N/A, not applicable; NSAIDs, non-steroidal antiinflammatory drugs; PPI, proton pump inhibitor; QD, once daily; SD, standard deviation.

twice-daily dosing in all categories except for emergency room visits. The mean total GERD-related costs in the postindex period for patients on twice-daily dosing were almost twice that of patients on once-daily dosing ( $\$ 3749$ versus $\$ 2065$, respectively, $P<0.0001$ ).

\section{Multivariate results}

The results of the generalized linear model for overall costs during the post-index period showed that patients on twice-daily dosing incurred significantly higher mean costs, after controlling for age, gender, Deyo-Charlson Comorbidity Index score, and diagnosis of Barrett's esophagus (Table 3, model 1). Similarly, and after controlling for the same variables, the generalized linear model for post-index GERD-related expenditure showed significantly higher costs for patients on twice-daily dosing (Table 3, model 2).
The generalized linear model showed that patients on twice-daily dosing had $37 \%$ higher annual total health care costs compared with once-daily users, with once-daily users having an annual cost of $\$ 10,269$ versus $\$ 14,061$ for patients on twice-daily dosing. Further, a two-part regression model showed that patients on twice-daily dosing had $56 \%$ higher annual GERD-related costs compared with once-daily users, with total annual GERD-related costs of \$1269 in once-daily users and \$2266 in patients on twice-daily dosing (Table 3).

\section{Discussion}

Prior studies have demonstrated significant costs related to management of patients with GERD compared with controls. The burden of direct and indirect costs has been estimated to be approximately $\$ 10$ billion a year in the US., ${ }^{3,18}$ One retrospective study from 2001 to 2004 utilized a large employer 
A

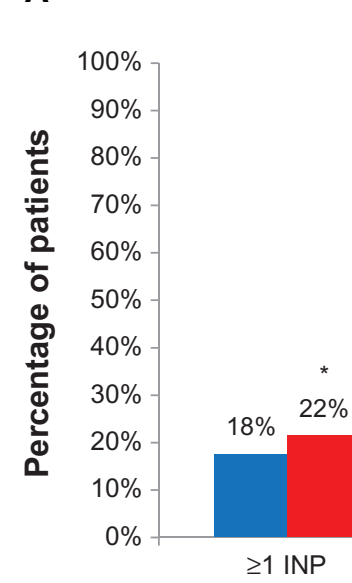

B

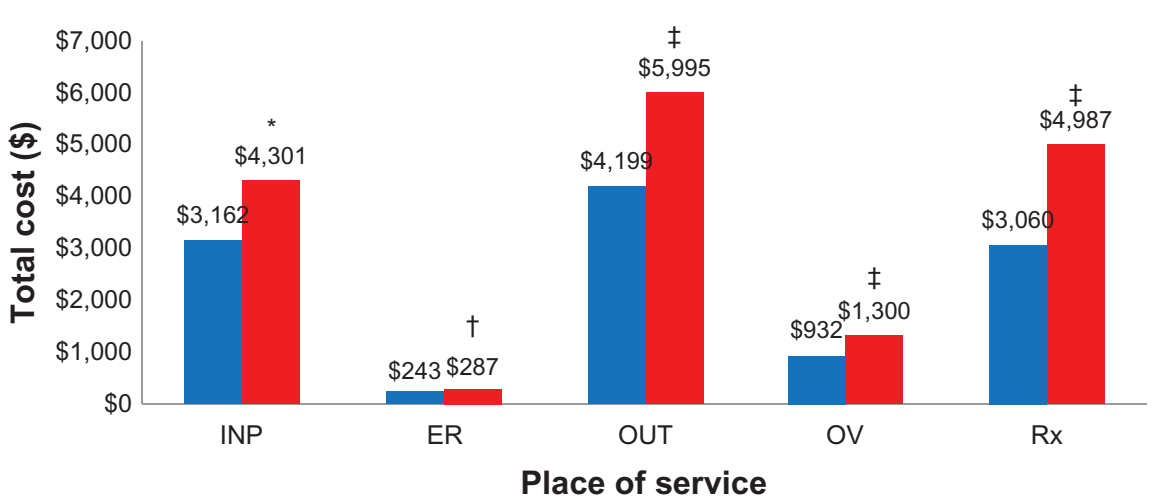

All-cause health care utilization

Place of service

All-cause health care cost
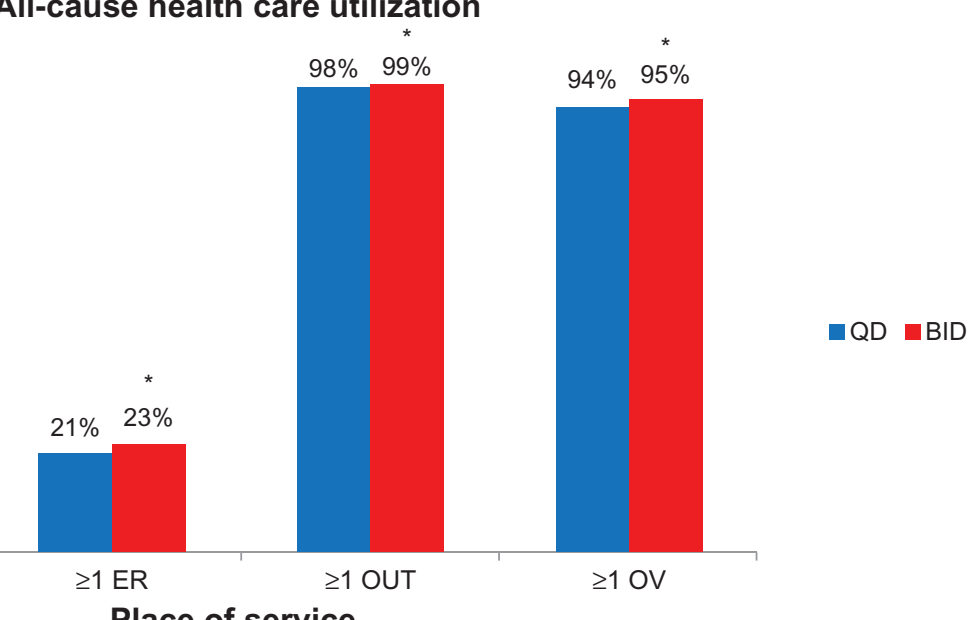

$\square \mathrm{QD} \square \mathrm{BID}$

Figure I All-cause health care utilization and cost of once-daily and twice-daily proton pump inhibitor use (I2-month post-index period)

Notes: Twice-daily dosing was associated with significantly greater overall health care utilization and costs compared with once-daily dosing. $* P<0.000 \mathrm{I} ;{ }^{\dagger} P=0.25$; $\ddagger P<0.000 \mathrm{I}$. Abbreviations: BID, twice daily; ER, emergency room visit; INP, inpatient hospitalization; OUT, outpatient service; OV, physician office visit; QD, once daily; Rx, pharmacy prescriptions.

database to evaluate GERD-related costs among 11,653 eligible employees with a primary, secondary, or tertiary diagnosis of GERD. Among these patients, the total health care-related costs were greater by $\$ 3355$ for patients with GERD compared with those without the condition $(\$ 6878$ versus $\$ 3522$, respectively). ${ }^{19}$ In addition, the study found that overall medical costs for GERD-afflicted employees were \$2318 (119\%) higher than for workers without the condition. A breakdown of expenditure showed that direct medical costs were $65 \%$, prescription drugs were $17 \%$, and indirect costs were $19 \%$ of total disease-related expenditure.

Few studies conducted in sizeable patient databases have examined the proportions of patients with GERD treated with once-daily or twice-daily PPI therapy, and some have estimated different aspects of the costs incurred by such patients. ${ }^{2-4}$ There is a marked absence of data regarding the demographic factors, health care resource utilization, and costs attributable to once-daily and twice-daily PPI use. The current study has attempted to address this gap by studying a large population of patients with GERD who were prescribed PPI medications, predominantly with once-daily usage but with a substantial segment $(n=25,627$, or $10 \%$ of the cohort) using twice-daily PPI, which allowed for meaningful comparisons. Our results indicate that twice-daily use was associated with significantly higher utilization of health care resources and associated costs for inpatient hospitalizations, emergency room visits, outpatient services, physician office visits, endoscopy procedures, and pharmacy services.

While the proportion of patients using twice-daily PPI therapy was lower in our study than in the reported literature, the differences may be accounted for by varying study designs. ${ }^{16}$ Our study identified patients using medical and pharmacy claims to define patients with GERD, whereas previous studies have used self-reported survey data. Additionally, once-daily and twice-daily categorization was defined using information from the entire follow-up period, 


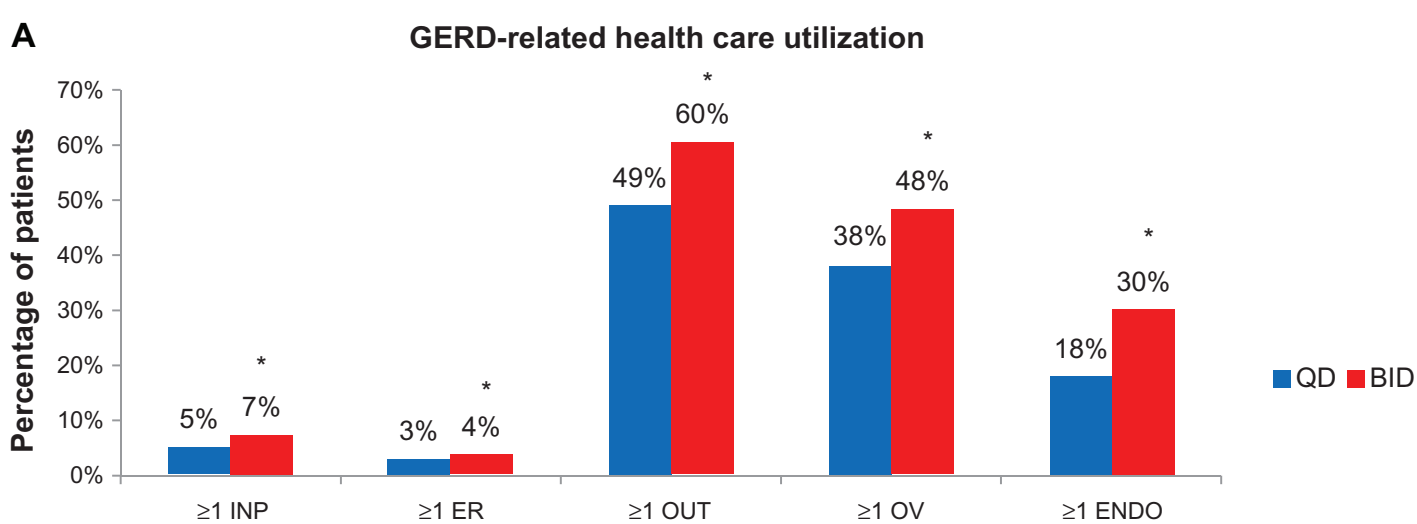

B

GERD-related health care cost

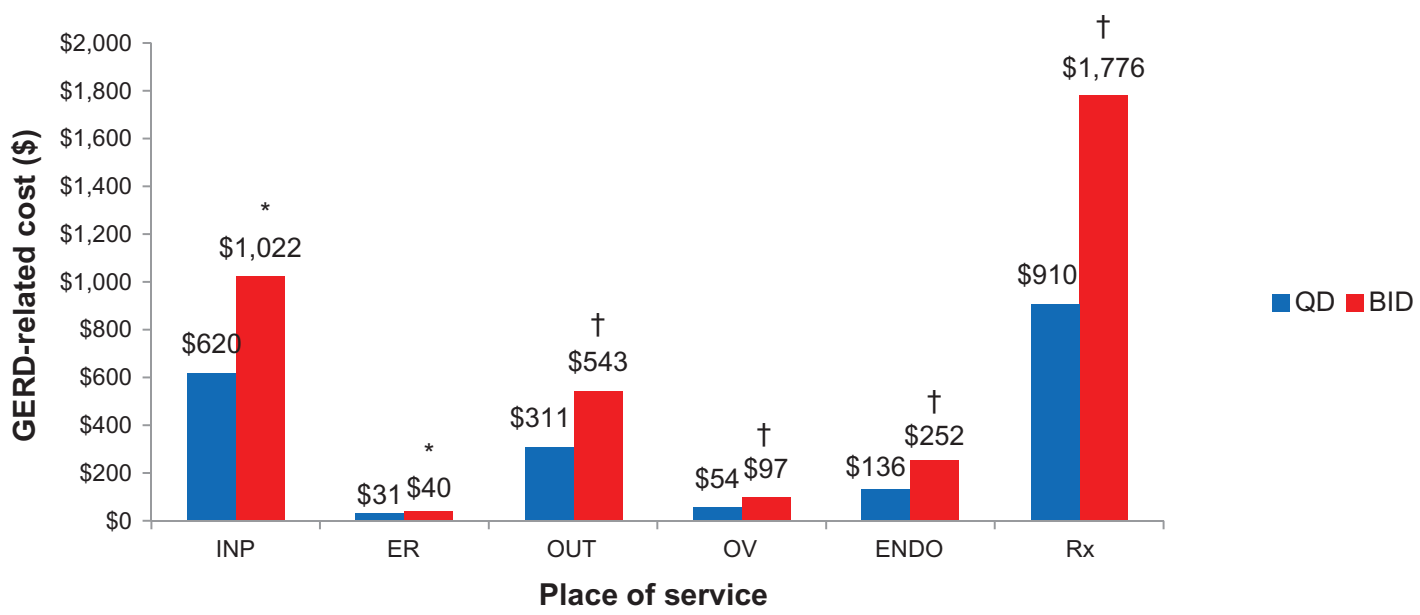

Figure 2 GERD-related health care utilization and cost of once-daily and twice-daily proton pump inhibitor use (I2-month post-index period).

Notes: GERD-related health care utilization and costs were higher for patients receiving twice-daily dosing than those receiving once-daily dosing. $* P<0.0$ I; ${ }^{\dagger} P<0.000 \mathrm{I}$. Abbreviations: BID, twice daily; ENDO, endoscopy procedures; ER, emergency room visit; GERD, gastroesophageal reflux disease; INP, inpatient hospitalization; OUT, outpatient service; OV, physician office visit; QD, once daily; Rx, pharmacy prescriptions.

not solely information reported on the index date. While this approach has not been reported in the literature, it has allowed for a more robust group assignment by capturing the treatment patterns for the entire year after initiation of PPI therapy. Given that the prevalence of twice-daily users may vary in different populations, partially related to the reasons stated above and practice management styles, the key point of this paper is the marked difference in health care utilization and costs for patients using twice-daily PPI therapy.

Patients with GERD who were on twice-daily PPI dosing had significantly more comorbidities, as indicated by their Deyo-Charlson Comorbidity index scores. Compared with once-daily PPI users, a greater proportion of twice-daily PPI users also had medical claims for Barrett's esophagus. While there is no consensus about the treatment of Barrett's esophagus, many patients are prescribed twice-daily PPIs as a first-line therapy and may stay on this course of treatment in order to reduce the future risk of dysplasia and/or adenocarcinoma. ${ }^{15,20,21}$ However, the majority of the patients did not have a Barrett's esophagus claim during the identification period, and can be reliably assumed to have taken a PPI for their GERD-related symptoms.

In this retrospective cohort study, we reported the clinical and demographic characteristics and health care utilization and costs for a large cohort of commercially insured patients on PPI therapy for GERD. We observed significant differences in the utilization of health care services between the patients treated once daily and twice daily. A smaller proportion of patients on once-daily dosing in this analysis required hospitalization, emergency room visits, outpatient services, physician office visits, and endoscopy procedures. Patients on once-daily dosing incurred significantly lower costs for emergency room visits, outpatient services, physician office 
Table 3 Multivariate results for total and GERD-related cost in the 12-month pre-index period

\begin{tabular}{|c|c|c|c|c|c|c|}
\hline \multirow[t]{2}{*}{ Model variables } & \multicolumn{3}{|c|}{ Model I (total cost) } & \multicolumn{3}{|c|}{ Model 2 (GERD-related cost) } \\
\hline & $\overline{\text { OR }}$ & $95 \% \mathrm{Cl}$ & $P$-value & OR & $95 \% \mathrm{Cl}$ & $P$-value \\
\hline \multicolumn{7}{|l|}{$\mathrm{BID} / \mathrm{QD}$} \\
\hline BID & 1.37 & $|.33-1.4|$ & $<0.0001$ & 1.35 & I.27-1.44 & $<0.000$ I \\
\hline QD (ref group) & - & - & - & - & - & - \\
\hline \multicolumn{7}{|l|}{ Age } \\
\hline $18-24$ & 0.84 & $0.79-0.90$ & $<0.0001$ & 0.83 & $0.72-0.95$ & 0.0087 \\
\hline $25-34$ & 0.71 & $0.69-0.73$ & $<0.000$ I & 0.78 & $0.72-0.85$ & $<0.0001$ \\
\hline $35-44$ & 0.77 & $0.75-0.79$ & $<0.0001$ & 0.84 & $0.79-0.89$ & $<0.0001$ \\
\hline $45-54$ & 0.88 & $0.86-0.90$ & $<0.0001$ & 0.93 & $0.88-0.98$ & 0.0069 \\
\hline $55-64$ (ref) & - & - & - & - & - & - \\
\hline \multicolumn{7}{|l|}{ Gender } \\
\hline Female & 1.17 & $1.15-1.20$ & $<0.000$ I & 1.04 & $1.00-1.09$ & 0.0664 \\
\hline Male (ref group) & - & - & - & - & - & - \\
\hline \multicolumn{7}{|l|}{ Region } \\
\hline Northeast & 1.07 & $1.03-1.10$ & $<0.0001$ & 1.38 & $1.28-1.49$ & $<0.0001$ \\
\hline Central & 0.91 & $0.89-0.93$ & $<0.0001$ & 1.06 & $1.01-1.12$ & 0.0293 \\
\hline Southeast & 0.85 & $0.83-0.87$ & $<0.0001$ & 0.76 & $0.72-0.80$ & $<0.0001$ \\
\hline West (ref group) & - & - & - & - & - & - \\
\hline \multicolumn{7}{|c|}{ Pre-index Barrett's esophagus indicator } \\
\hline Yes & 0.92 & $0.87-0.98$ & 0.0064 & 1.08 & $0.94-1.24$ & 0.2659 \\
\hline No & - & - & - & - & - & - \\
\hline \multicolumn{7}{|c|}{ Pre-index Deyo-Charlson Comorbidity Index score } \\
\hline & $\mathrm{I} .44$ & $1.43-1.45$ & $<0.0001$ & 1.22 & $1.19-1.24$ & $<0.0001$ \\
\hline Predicted cost & Mean* & & Std error & & Mean** & Std error \\
\hline QD & $\$ 10,269$ & & $\$ 82$ & & $\$ 1,269$ & $\$ 1$ \\
\hline BID & $\$ 14,06 \mid$ & & $\$ 220$ & & $\$ 2,266$ & $\$ 9$ \\
\hline
\end{tabular}

Notes: *Generalized linear model was used to estimate the total all cause costs using an underlying gamma distribution with log link function; **two-part regression model was used to estimate the GERD-related costs.

Abbreviations: BID, twice daily; $\mathrm{Cl}$, confidence interval; GERD, gastroesophageal reflux disease; OR, odds ratio; QD, once daily; ref, reference; std, standard.

visits, and endoscopy services. Although the costs associated with patients on once-daily doses for inpatient hospitalization were lower than those for patients on twice-daily doses, the difference was not statistically significant. Overall, the total GERD-related costs in the post-index period were significantly greater for patients on twice-daily doses in comparison with those on once-daily doses.

While symptom control was not assessed in the course of this study, there may be unobserved factors that can impact the therapeutic option (once-daily versus twice-daily), which, as our study demonstrates, provides evidence on the differences in cost and health care utilization of twice-daily versus once-daily users. The results demonstrate that patients on twice-daily doses may have had more severe disease, and that there were differences in cost and utilization. However, there is evidence to suggest that most patients with GERD treated twice daily can be successfully stepped down to once-daily PPI therapy, ${ }^{22}$ which would decrease the overall medication cost. For this reason, it may be worthwhile evaluating patients who use PPIs twice-daily on a regular basis to assess any potential clinical and cost benefits that may result from changing their medication patterns.
Limitations of our analysis include the fact that we were unable to collect information regarding timing of PPI administration, which may have affected clinical efficacy. In addition, we were not able to obtain data regarding the presence or absence of erosive esophagitis. Also, the claims data used in this study did not explicitly describe disease severity, and because of limits in the study timeline, it was not possible to ascertain the duration of disease among the subjects. Claims data have inherent limitations, the most substantial of which may be the absence of randomization between treatment cohorts. In this analysis, we used a number of statistical tools to adjust for this acknowledged bias. In addition, the claims data may have had coding errors and unintentional duplications, among other handling issues. In this study, the absence of pharmacy claims was used as the basis for measuring noncompliance. However, because of the reliance on claims data, it cannot be definitively stated that patients were not on another kind of GERD medication (such as over-the-counter formulations) and that the patient did not receive medication from another source (eg, samples from a family physician). Twice-daily and once-daily dosing and switching among PPIs and among 
doses could also be driven by insurance-related factors. The reasons for switching in our study population were not identifiable.

\section{Conclusion}

In this study, patients on twice-daily PPIs had greater comorbidities and incurred greater total and GERD-related health care utilization and costs. Because PPIs are typically the treatment of choice for GERD, the differences associated with once-daily versus twice-daily dosing regimens with regard to treatment costs and resource utilization as shown here may have important implications for future treatment decisions.

\section{Disclosure}

Funding for this study and medical writing assistance was provided to HealthCore Inc, an independent contract research organization, by Takeda Pharmaceuticals International Inc. Special thanks are extended to Bernard Tulsi and Betsy Marks, medical writers at HealthCore Inc, for their continued effort and support throughout the manuscript development process. LG is a consultant to Takeda and Eisai Inc, and has received research support from Santarus Inc. RM is an employee of Takeda Pharmaceuticals International Inc, DE, SK, and JS are employees of HealthCore Inc, and LH was an employee of HealthCore at the time this research was conducted.

\section{References}

1. Locke GR III, Talley NJ, Fett SL, Zinsmesiter AR, Melton LJ III. Prevalence and clinical spectrum of gastroesophageal reflux: a population-based study in Olmsted County, Minnesota. Gastroenterology. 1997;112: $1448-1456$.

2. Friedenberg FK, Hanlon A, Vanar V, et al. Trends in gastroesophageal reflux disease as measured by the National Ambulatory Medical Care Survey. Dig Dis Sci. 2010;55:1911-1917.

3. Shaheen NJ, Hansen RA, Morgan DR, et al. The burden of gastrointestinal and liver diseases, 2006. Am J Gastroenterol. 2006;101:2128-2138.

4. Wahlqvist P, Karlsson M, Johnson D, Carlsson J, Bolge SC, Wallander MA. Relationship between symptom load of gastrooesophageal reflux disease and health-related quality of life, work productivity, resource utilization and concomitant diseases: survey of a US cohort. Aliment Pharmacol Ther. 2008;27:960-970.

5. Frank L, Kleinman L, Ganoczy D, et al. Upper gastrointestinal symptoms in North America: prevalence and relationship to healthcare utilization and quality of life. Dig Dis Sci. 2000;45:809-818.

6. Henke CJ, Levin TR, Henning JM, Potter LP. Work loss costs due to peptic ulcer disease and gastroesophageal reflux disease in a health maintenance organization. Am J Gastroenterol. 2000;95:788-792.

ClinicoEconomics and Outcomes Research

\section{Publish your work in this journal}

ClinicoEconomics \& Outcomes Research is an international, peerreviewed open-access journal focusing on Health Technology Assessment, Pharmacoeconomics and Outcomes Research in the areas of diagnosis, medical devices, and clinical, surgical and pharmacological intervention. The economic impact of health policy and health systems
7. Liker H, Hungin P, Wiklund I. Managing gastroesophageal reflux disease in primary care: the patient perspective. J Am Board Fam Pract. 2005; 18:393-400.

8. Kahrilas PJ, Shaheen NJ, Vaezi MF, et al. American Gastroenterological Association medical position statement on the management of gastroesophageal reflux disease. Gastroenterology. 2008;135:1383-1391.

9. Vasiliadis KV, Viazis N, Vlachogiannakos J, et al. Efficacy of three different dosages of esomeprazole in the long-term management of reflux disease: a prospective, randomized study, using the wireless Bravo pH system. Am J Gastroenterol. 2010;105:308-313.

10. Hemmink GJ, Bredenoord AJ, Weusten BL, Monkelbaan JF, Timmer R, Smout AJ. Esophageal $\mathrm{pH}$-impedance monitoring in patients with therapy-resistant reflux symptoms: 'on' or 'off' proton pump inhibitor? Am J Gastroenterol. 2008;103:2446-2453.

11. MacKalski BA, Ilnyckyj A. Esophageal $\mathrm{pH}$ testing in patients refractory to proton pump inhibitor therapy. Can J Gastroenterol. 2008;22: 249-252.

12. Coté GA, Ferreira MR, Rozenberg-Ben-Dror K, Howden CW. Programme of stepping down from twice daily proton pump inhibitor therapy for symptomatic gastro-oesophageal reflux disease associated with a formulary change at a VA medical center. Aliment Pharmacol Ther. 2007;25:709-714.

13. Ahmed TF, Khandwala F, Abelson TI, et al. Chronic laryngitis associated with gastroesophageal reflux: prospective assessment of differences in practice patterns between gastroenterologists and ENT physicians. Am J Gastroenterol. 2006;101:470-478.

14. Vaezi MF. Laryngeal manifestations of gastroesophageal reflux disease. Curr Gastroenterol Rep. 2008;10:271-277.

15. DeVault KR, Castell DO. Updated guidelines for the diagnosis and treatment of gastroesophageal reflux disease. Am J Gastroenterol. 2005; 100:190-200.

16. Chey WD, Mody RR, Wu EQ, et al. Treatment patterns and symptom control in patients with GERD: US community-based survey. Curr Med Res Opin. 2009;25:1869-1878.

17. Gerson LB, Bonafede M, Princic N, Gregory C, Farr A, Balu S. Development of a refractory gastro-esophageal reflux score using an administrative claims database. Aliment Pharmacol Ther. 2011;34:555-567.

18. Sandler RS, Everhart JE, Donowitz M, et al. The burden of selected digestive diseases in the United States. Gastroenterology. 2002;122: 1500-1511.

19. Brook RA, Wahlqvist P, Kleinman L, Wallander MA, Campbell SM, Smeeding JE. Cost of gastro-oesophageal reflux disease to the employer: a perspective from the United States. Aliment Pharmacol Ther. 2007;26:889-898.

20. El-Serag HB, Wieman M, Richardson P. The use of acid-decreasing medication in veteran patients with gastro-oesophageal reflux disorder with and without Barrett's oesophagus. Aliment Pharmacol Ther. 2008;27:1293-1299.

21. Klinkenberg-Knol EC, Festen HP, Meuwissen SG. Pharmacological management of gastro-oesophageal reflux disease. Drugs. 1995;49: 695-710.

22. Fass R, Inadomi J, Han C, Mody R, O’Neil J, Perez MC. Maintenance of heartburn symptom relief in patients stepped-down from twicedaily proton pump inhibitor to once-daily dexlansoprazole MR. Am J Gastroenterol. 2011;106 Suppl 2:S5-S6.

\section{Dovepress}

organization also constitute important areas of coverage. The manuscript management system is completely online and includes a very quick and fair peer-review system, which is all easy to use. Visit http://www.dovepress.com/testimonials.php to read real quotes from published authors. 